\title{
Instability Criteria for Vehicles in Motion Exposed to Flood Risks
}

\author{
Syed Muzzamil Hussain Shah ${ }^{1, *}$, Zahiraniza Mustaffa ${ }^{1}$, Do Kyun Kim ${ }^{1}$, and \\ Khamaruzaman Wan Yusof ${ }^{1}$ \\ ${ }^{1}$ Department of Civil and Environmental Engineering - Universiti Teknologi PETRONAS, 32610, \\ Seri Iskandar, Perak, Malaysia
}

\begin{abstract}
Flooded roads have somewhat become a norm to the society and among the damages that floods can pose, there are fatalities and harm caused to people. Floating debris such as vehicles, manipulated by floodwaters could potentially cause harm not only to the public safety but also towards the public and private-owned properties. In the past, research on vehicle's instabilities have been solely dedicated to static vehicles which are normally translated as vehicles parked on road surface. A vehicle when exposed to floodwater get influenced by different hydrodynamic forces and becomes prone to different instability modes, namely sliding, floating and toppling. Outcomes on such modes are somehow recognised in the works on static vehicles, but the mechanics of a moving vehicle under such influences have not been studied. Herein the influence of floodwater flows on the vehicle attempting to cross a flooded path (partial submergence) is presented. With that regards, a non-stationary model vehicle with the scale ratio of 1:10 (Perodua Viva) was used and a series of experiments were conducted. Moreover, a new formula to estimate the incipient velocity for a moving vehicle has been introduced and the prediction accuracy of the proposed formula has been validated using experimental data. Measurements were taken including approaching velocities and water depths, through which the instability was computed.
\end{abstract}

\section{Introduction}

In recent years, the probability of flood occurrence has raised due to the considerable change in the meteorological system which has increased the risk of vehicle instability in floodwaters on causeways and streets [1]. This may exhibit very undesirable dynamic behaviour to the vehicle under certain conditions [2] causing the vehicle to become unbalanced either by floating, when the water depth is high and flow velocity is low or by losing the frictional resistance between the tires and the ground surface when the flow velocity is high and the water depth is low [1]. In this way, vehicles might be considered as massive debris washed away by the flood which could compromise pedestrian safety as well as generate significant economic damages [3]. A clear illustration of the similar damages is the heavy downpour which caused a devastating flash flood at the low-lying areas near

*Corresponding author: syed.muzzamil_g03359@utp.edu.my 
Sungai Pinang and Sungai Air Itam in Penang, Malaysia on $15^{\text {th }}$ September 2017 as shown in Figure 1. The department of Irrigation and Drainage (DID), Malaysia reported that both the rivers reached the highest levels recorded i.e. $3.2 \mathrm{~m}$ (Sungai Pinang) and $7.3 \mathrm{~m}$ (Sungai Air Itam). The rainfall recorded at Sungai Pinang and Sungai Air Itam station was $198 \mathrm{~mm}$ and $120.5 \mathrm{~mm}$, respectively. Massive traffic gridlock at the roads was witnessed due to the submergence of the vehicles in floodwaters as most of the areas were flooded between $0.1 \mathrm{~m}$ to $0.6 \mathrm{~m} \mathrm{[4].}$

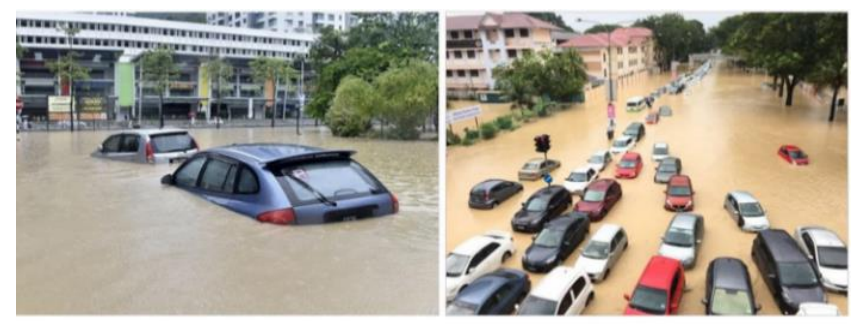

Fig. 1. Flooded vehicles in the 2017 George Town, Penang (Malaysia) flood [4].

Hazards related to the vehicles exposed to floodwater are based on the determination of their stability threshold assessed from the hydraulic variables i.e. flow water depth and velocity [5], [6] and [7]. A vehicle's stability will be compromised when the hydraulic variables exceeds a certain limit, similar to the stability threshold of pedestrians exposed to water flows [8], [9] and [10]. In case of vehicles, characteristics like weight, shape and design determines the level of stability [3]. Existing design guidelines are based on the product of flow depth and velocity obtained during the experimental investigation and the theoretical analysis of the stationary vehicle in late 1960's and early 1970's. However, today's vehicle on roads are different in design from the past, where new improvements in these vehicles have been taken into consideration therefore, the results of these earlier studies may no longer hold for contemporary vehicles [11]. Although people safety is the primary aim of any flood risk management strategy, the studies on vehicles instability under water flow are sparse [12]. Thus, there is a need to address vehicles in motion endangered by floodwaters.

Herein, the instability criteria for partially submerged vehicle in motion has been investigated and a mechanics-based incipient velocity formula was derived. With that regards, a moving Perodua Viva which represents the typical size of Malaysian passenger cars was modelled on the scale ratio of 1:10, fulfilling all the conditions of similitude. The vehicle model was tested under varying discharges and water depth conditions. The water levels were set in close resemblance to the limits allowed for the height of car. Measurements were taken including approaching velocities and water depths, through which the instability was computed.

\section{Theoretical Background}

Moving water particularly floodwater flows create hydrodynamic forces which can move vehicles on urban floodplains. In case of parked vehicles, the flow usually exerts three forces, including buoyancy force $\left(\mathrm{F}_{\mathrm{B}}\right)$, lift force $\left(\mathrm{F}_{\mathrm{L}}\right)$ and drag force $\left(\mathrm{F}_{\mathrm{D}}\right)$. An additional force which is called frictional force $\left(\mathrm{F}_{\mathrm{R}}\right)$ is also produced due to the contact between the tires and the ground surface to resist the vehicle from sliding. Therefore, in this case, stability of the vehicle is governed by the above forces including gravitational force $\left(\mathrm{F}_{\mathrm{G}}\right)$ [13].

The buoyancy force is an upward force exerted by a fluid that opposes the weight of the immersed object. Hence, when the buoyancy force together with the lift force is greater than the vehicle weight, mode of floating instability is observed. This force can be expressed as: 


$$
\mathrm{F}_{\mathrm{B}}=\rho g \mathrm{~V}
$$

where, $\rho$ is the water density, $g$ is the acceleration due to gravity and $\mathrm{V}$ is the submerged volume.

In recent studies, buoyancy force alone has been accounted responsible for floating instability of vehicles in the flowing water, whereas the influence of lift force has been disregarded completely while estimating the vertical pushing forces [14], [15] and [16]. Although, for high velocities the effect of buoyancy could be neglected, thereby considering only the effect of lift force [17]. Herein the study was performed under sub-critical flow conditions therefore, only the influence of buoyancy force was considered for the estimation of floating instability. However, lift force is a component of a force which is flowing past the surface of a body and can be given as:

$$
\mathrm{F}_{\mathrm{L}}=\frac{1}{2} \rho \mathrm{C}_{\mathrm{L}} \mathrm{A}_{\mathrm{L}} \mathrm{v}^{2}
$$

where, $C_{L}$ is the lift coefficient, $A_{L}$ is acting area by the lift force and $v$ is the flow velocity [17].

In fluid dynamics, drag acts opposite to the relative motion of any object moving with respect to a surrounding fluid. The drag force relies on the area of changing momentum, fluid velocity and its density. It can be expressed as:

$$
\mathrm{F}_{\mathrm{D}}=\frac{1}{2} \rho \mathrm{C}_{\mathrm{D}} \mathrm{A}_{\mathrm{D}} \mathrm{V}^{2}
$$

where, $C_{D}$ is the drag coefficient, $A_{D}$ is the submerged area projected normal to the flow, and $\mathrm{V}$ is the velocity of the flow [15].

In context of vehicle stability in floodwaters, the friction force is the primary hydrodynamic force that acts between the vehicle tires and the floodplain surface. This force prevents the vehicle from sliding and is the total resistance acting on the vehicle tires by the floodplain surface. The general formula for the friction force can be expressed as:

$$
\mathrm{F}_{\mathrm{R}}=\mu \mathrm{F}_{\mathrm{N}}
$$

where, $\mu$ is the coefficient of friction, set at 0.3 after Bonham and Hattersley (1967); and $\mathrm{F}_{\mathrm{N}}$ is the normal reaction force from the ground which is equivalent to the net weight of the vehicle (axle load in dry condition minus vertical pushing forces) [16].

A stationary vehicle when exposed to floodwater is influenced by different hydrodynamic forces as discussed earlier. On the other hand, the criterion of vehicle instability for a moving vehicle differs as it gets in contact with water. This happens due to two main factors i.e. rolling resistance and driving force which have been introduced in this study. Herein the incipient velocity formula for a non-stationary vehicle moving on a flat road surface, perpendicular to the direction of flow has been proposed. For the convenience of analysis, the instability thresholds for the partially submerged vehicle have been analyzed only for sub-critical flow states. Under such circumstances, as the non-stationary vehicle starts to slide along a road surface, the drag force induced by the incoming flow is just balanced by the frictional force and the driving force caused by the vehicle engine. When this occurs, the influence of drag force acts in two directions, namely at the front side as the vehicle moves into the water and at the side end by the direction of flow. Similarly, the type of friction between the surface and the tires which are usually cylindrical, changes. For parked vehicles (brakes applied), the fricition coeffcient between $\mu=0.3$ to $\mu=1$ has been proposed by different authors [18] and [19]. Herein, the friction coefficient for a moving vehicle on the wet road conditions was experimentally obtained in two directions. Prior to estimating the friction coefficient, the Manning roughness coefficient of the designed platform was determined which was found to be 0.017 . This value nearly matches to the Manning coefficient for asphalt pavements (rough texture - 0.016) [20]. Moreover, the wheels of the vehicle were made from the same rubber material to ensure proper friction between the tires and the road surface. However, the rolling friction can be determined as: 


$$
\mathrm{F}_{\mathrm{RO}}=\frac{\mathrm{Wb}}{\sqrt{\mathrm{r}^{2}-\mathrm{b}^{2}}}
$$

where, $F_{\mathrm{RO}}$ is the rolling resistive force required to keep the tires rolling, $\mathrm{W}$ is the weight of the load, $b$ is the distance from the middle of the centre of the axle toward the tire no longer touching the ground and $\mathrm{r}$ is the radius of the tire [21].

The coefficient of rolling resistance can also be determined experimentally by following the similar method as proposed by Bonham and Hattersley (1967) and Gordan and Stone (1973). To do so, the horizontal force required by the tires to rotate can be estimated manually by using a spring balance. This force when divided by the model weight estimates the coefficient of rolling friction. Thus, the resistive force required to keep the tires rolling can also be given as:

$$
\mathrm{F}_{\mathrm{RO}}=\mu_{\mathrm{RO}} \cdot \mathrm{N}
$$

where, $\mu_{\mathrm{RO}}$ is the coefficient of rolling friction and $\mathrm{N}$ is the net weight of the vehicle. Thus, it can also be said:

$$
\mathrm{F}_{\mathrm{RO}}=\frac{\mathrm{Wb}}{\sqrt{\mathrm{r}^{2}-\mathrm{b}^{2}}}=\mu_{\mathrm{RO}} \cdot \mathrm{N}
$$

Lastly, an additional force caused by the vehicle engine known as driving force, $\left(\mathrm{F}_{\mathrm{DV}}\right)$ is introduced. This force opposes the drag force caused by the incoming fluid and acts in the opposite direction to vehicle motion. The driving force caused by the engine can be given as:

$$
\mathrm{F}_{\mathrm{DV}}=\mathrm{ma}
$$

where, $\mathrm{m}$ is the mass of the vehicle and $\mathrm{a}$ is the average acceleration which can be defined as:

$$
\mathrm{a}=\frac{\mathrm{v}_{\mathrm{f}}-\mathrm{v}_{\mathrm{o}}}{\mathrm{t}}
$$

where, $v_{f}$ is the final velocity, $v_{o}$ is the initial velocity and $t$ is the time taken by the initial velocity to reach final velocity. For the vehicles moving with the constant velocity in water, the net force acting on it becomes zero therefore, the influence of driving force becomes negligible.

The forces acting on the partially submerged moving vehicle in floodwater are illustrated in Figure 2.

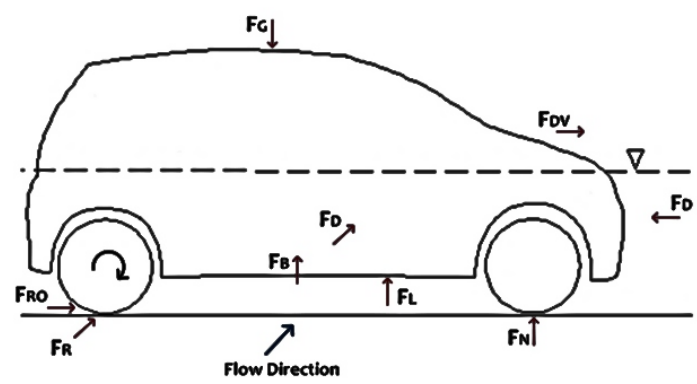

Fig. 2. Forces acting on a non-stationary vehicle in water.

\section{Formula Derivation}

In previous studies, the corresponding criteria of instability threshold for the parked vehicles was given when the drag force induced by the incoming flow is just balanced by the frictional force preventing the vehicle from sliding [13], [14], [15], [22], [23] and [24] which can be given as:

$$
\mathrm{F}_{\mathrm{D}}=\mathrm{F}_{\mathrm{R}}
$$

where, $F_{D}$ is the drag force and $F_{R}$ is the friction force.

Herein, the instability criteria for the vehicle moving perpendicular to the flow direction has been proposed which occurs when the drag force induced by the incoming flow is just 
balanced by the friction preventing the vehicle from sliding and the driving force caused by the vehicle engine. In this case, the influence of the drag force mainly acts on the vehicle side and it affects the front end of the vehicle as the vehicle enters the water. However, concerning friction force, rolling friction occurs when the vehicle starts to move. This friction is very low as the contact between the tires and the ground is for limited span of time, whereas the friction in the opposite direction is comparatively high. Nevertheless, the corresponding criterion of instability threshold for vehicles in motion can be given as:

$$
\begin{gathered}
F_{D}=F_{R O}+F_{R}+F_{D V} \\
\frac{1}{2} \rho C_{D} A_{D} V^{2}=F_{N}\left(\mu_{R O}+\mu\right)+F_{D V} \\
v=\sqrt{2 \times \frac{F_{N}\left(\mu_{R O}+\mu\right)+F_{D V}}{\rho C_{D} A_{D}}}
\end{gathered}
$$

where, $\mathrm{v}$ is the incipient velocity formula for the partially submerged vehicle based on the mechanical theory of sliding equilibrium, $\mathrm{F}_{\mathrm{N}}$ is the normal reaction force from the ground which is equivalent to the net weight of the vehicle, $\mu_{\mathrm{RO}}$ is the coefficient of rolling resistance, $\mu$ is the friction coefficient acting between the tires and the ground surface (parallel to the flow direction), $F_{D V}$ is the driving force caused by the vehicle engine, $\rho$ is the water density, $C_{D}$ is the drag coefficient and $A_{D}$ is the submerged area projected normal to the flow.

\section{Methodology}

\subsection{Vehicle Specifications}

A physical scale model is completely similar to its real-world prototype and involves no scale effects if it satisfies mechanical similarity implying the following three criteria: geometric similarity; kinematic similarity; dynamic similarity [25], [26], [27], [28], [29], [30] and [31]. Herein, a moving Perodua Viva which represents the typical size of Malaysian passenger cars was modelled on the scale ratio of 1:10, fulfilling all the conditions of similitude. The model was tested under varying discharges and water depth conditions through which the instability was computed. The water levels were set in close resemblance to the limits allowed for the height of car. The specifications of both model and prototype are shown in Table 1.

Table 1. Vehicle Specifications.

\begin{tabular}{|c|c|c|c|c|c|}
\hline Vehicle & Scale & $\begin{array}{c}\text { Length } \\
(\mathbf{m m})\end{array}$ & $\begin{array}{c}\text { Width } \\
(\mathbf{m m})\end{array}$ & $\begin{array}{c}\text { Height } \\
(\mathbf{m m})\end{array}$ & $\begin{array}{c}\text { Kerb Weight } \\
(\mathbf{g})\end{array}$ \\
\hline \multirow{2}{*}{$\begin{array}{c}\text { Perodua } \\
\text { Viva }\end{array}$} & Prototype & 3575 & 1475 & 1530 & $\approx 800000$ \\
\cline { 2 - 6 } & Model $(1: 10)$ & 357.5 & 147.5 & 153.0 & 880 \\
\hline
\end{tabular}

\subsection{Experimental Setup}

Due to the flume limitations, experimental runs with the non-stationary model vehicle were carried in a physical model of a water retaining structure (pond) located at the hydraulics laboratory, Universiti Teknologi PETRONAS (UTP). The area of the retaining structure is $27 \mathrm{~m} \mathrm{x} 12 \mathrm{~m}$. The experimental area of about $5 \mathrm{~m} \mathrm{x} 4.25 \mathrm{~m}$ is made of loose bed (sand) where the designed platform was placed and the experimental runs were conducted. Prior to placing the platform on the loose bed, proper compaction was ensured so that study area remains flat and the water does not seep into the soil. Next, the platform was affixed into the sand so that it does not float during the experimental phase. A wooden plank of $1.2 \mathrm{~m}$ x $0.8 \mathrm{~m}$ was placed alongside the platform so that the flow turbulence can be diminished and the approaching 
flow can be properly estimated. The inflow Q was released into the pond from the inlet conduit.

A set of measurements for each experiment involved the velocity of the incoming flow (v) and water depth on the platform (y). Moreover, the time taken by the vehicle to reach a distance for the estimation of driving force $\left(\mathrm{F}_{\mathrm{DV}}\right)$ was also noticed. The velocity and water depth measurements were observed at the point of interest from a moveable hanging bridge located just above the study area. Water depth measurements were conducted by using a point gauge. The point gauge is a portable device that provides reading on a millimetre $(\mathrm{mm})$ scale. The velocity of the flow was measured using the current meter. The miniature head of the flow sensing probe can measure velocities as low as $5.0 \mathrm{~cm} / \mathrm{sec}$. The propellers attached to the current meter provide inputs to the data logger, thus velocity in the unit of $\mathrm{cm} / \mathrm{s}$ was recorded through its automatic conversion. A monitoring laser was used to observe the movement of the vehicle in water. The purpose of using the laser beam was to profoundly observe the instability of the vehicle either in $\mathrm{x}$ or $\mathrm{y}$ direction, as it was difficult to observe the vehicle movement through naked eyes. The laser was placed just above the platform on the hanging bridge.

After each run of experiment, the whole pond was allowed to drain and dry. Experimental data were collected for several flow conditions. Numerous combinations of pump (from where the flow was handled) and outlet (the opening of the gate was adjusted) were carried. It was done to observe the instability of the vehicle under different water depths and flow conditions. Three combinations of pump were selected i.e. low flows, moderate flows and high flows. Similarly, three combinations of the outlet were selected based on its opening i.e. $0.04 \mathrm{~m}, 0.06 \mathrm{~m}$ and $0.08 \mathrm{~m}$. A camcorder was also placed in the pond to record the experimental runs/instability points. The details of the experimental setup are shown in Figure 3.
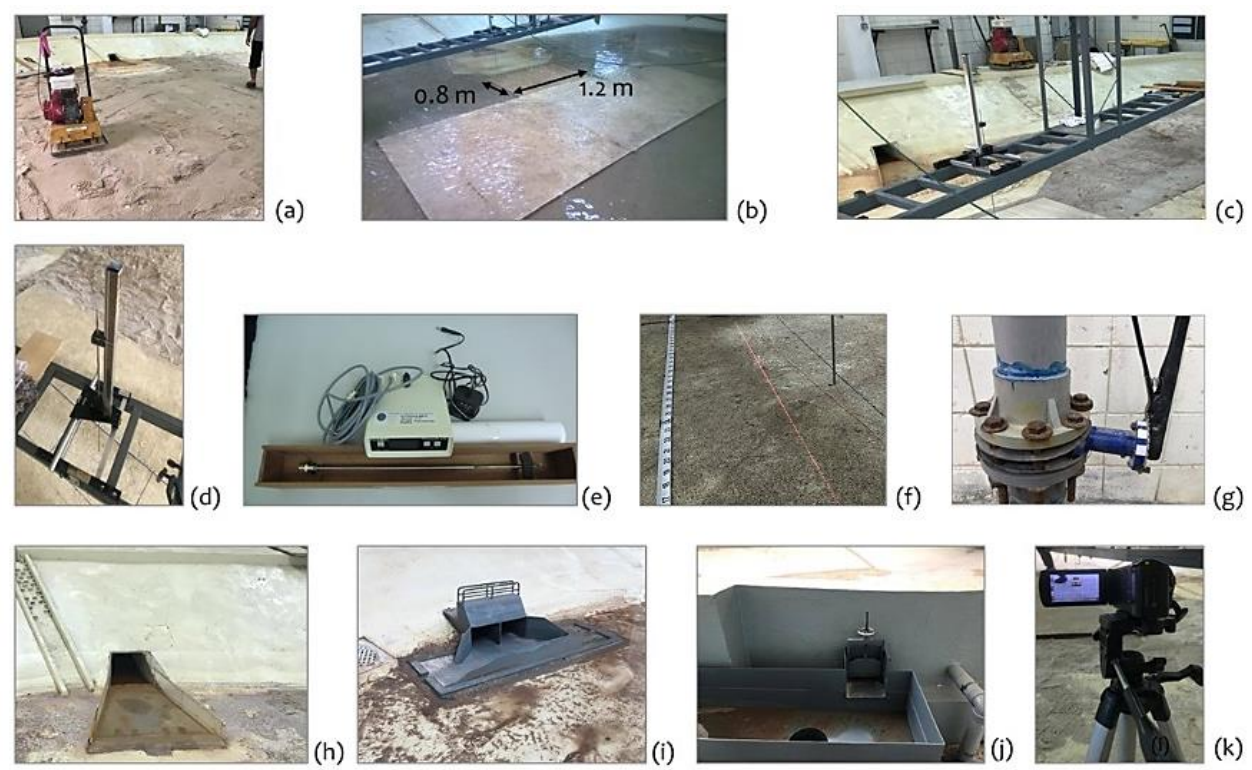

Fig. 3. Experimental Setup (a) Bed compaction, (b) Wooden plank, (c) Hanging bridge, (d) Point gauge, (e) current meter, (f) Laser beam, (g) pump, (h) Inlet, (i) Outlet, (j) Outlet catchment basin and (k) Camcorder. 


\section{Results and Discussions}

\subsection{Instability Threshold Points}

Detailed experiments with the model vehicle were conducted to investigate the influence of floodwater flows on the instability of the partially submerged vehicle. The mode of instability was observed only in one direction (vehicle moving perpendicular to the flow direction). Due to flume limitations, the range of water depths tested were between $0.039 \mathrm{~m}$ to $0.083 \mathrm{~m}$, whereas for the flow velocities the observed range was in between $0.25 \mathrm{~m} / \mathrm{s}$ to $0.60 \mathrm{~m} / \mathrm{s}$. The results showed that at shallow depths, high threshold velocities were needed to make the vehicle instable (sliding instability) as shown in Figure 4(a), whereas at low flow velocities, high water depths were needed to cause floating instability as shown in Figure 4(b). The critical water depth was noticed when it exceeded $0.0457 \mathrm{~m}$, as shown in Figure 5. This happened due to the impact of buoyancy force which exceeded vehicle weight. Herein, the study was performed under sub-critical flow conditions therefore, the influence of lift force for the estimation of vertical pushing forces was not taken into consideration. On the other hand, below critical water depth, mode of sliding instability was observed. Sliding instability occurred when the drag force caused by the incoming flow was greater than the friction force between the tires and ground, and the driving force of the car.
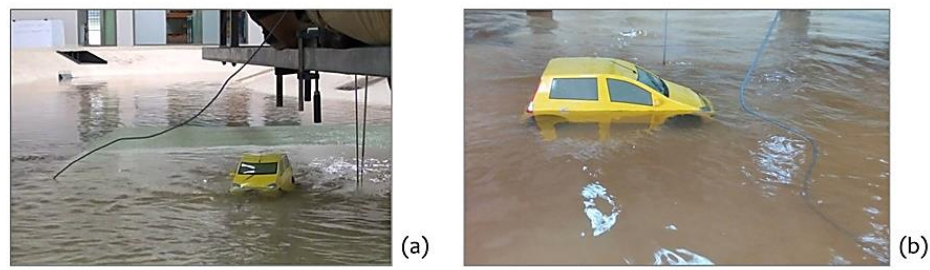

Fig. 4. Instability modes (a) Sliding and (b) Floating.

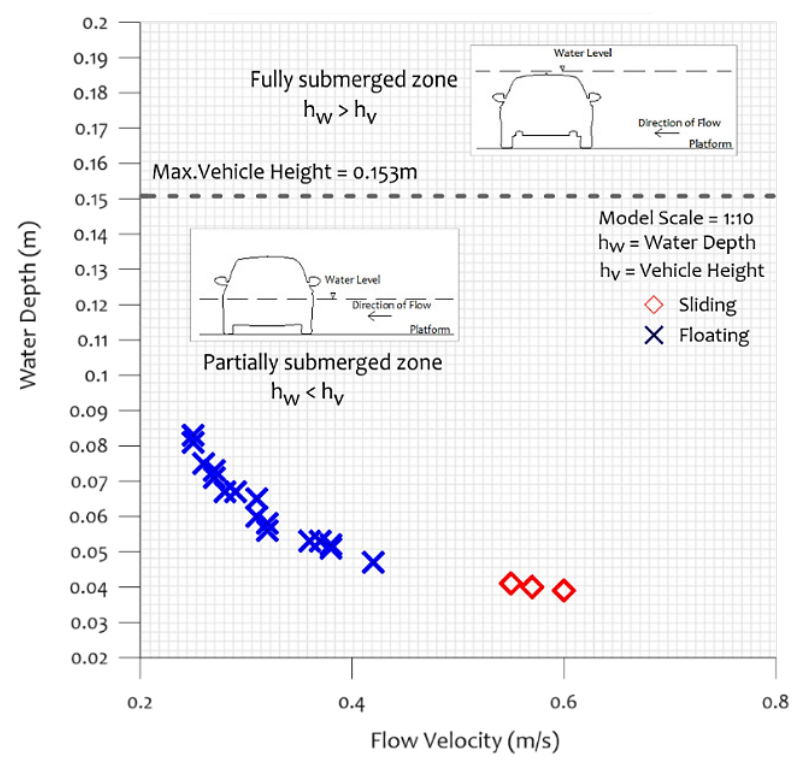

Fig. 5. Instability threshold for mobile vehicle. 


\subsection{Forces Estimation}

The following sections report on the forces, namely buoyancy, drag, friction and driving force, determined on a partially submerged moving vehicle in floodwaters as well as its corresponding behaviours at floating and sliding conditions under varying flow depths and velocities.

\subsubsection{Buoyancy force}

To determine the buoyancy force, submerged volume of the vehicle at different water depths was needed. Since the model was small with the complex design and proportions therefore, the body of the vehicle was precisely designed on scale using Auto-Cad (2007). It was then further modified and extruded using Solid-Works (2015). Lastly, the volume of the water displaced by the vehicle body was obtained using ANSYS (Static Structural, Workbench 15.0) as shown in Figure 6(a), (b) and (c). Similarly, to estimate the volume of the water displaced by the vehicle tires, same steps were followed as shown in Figure 6(a1), (b1) and (c1). The submerged volume of the body and the tires was then accumulated for the estimation of the up-thrust force at different water depths as shown in Table 2.
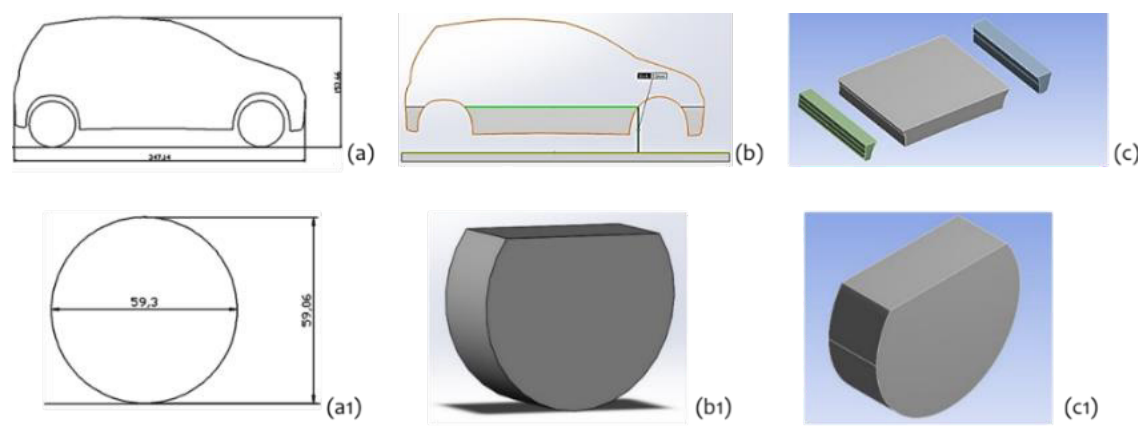

Fig. 6. Submerged volume (a) Body only and (a1) Tire only - AutoCad, (b) model extruded and (b1) vehicle tire extruded - SolidWorks, and (c) submerged volume of the body and (c1) submerged volume of the tire - ANSYS.

Table 2. Buoyancy Force.

\begin{tabular}{|c|c|c|c|c|}
\hline S. No & $\begin{array}{c}\text { Velocity } \\
(\mathbf{m} / \mathbf{s})\end{array}$ & $\begin{array}{c}\text { Depth } \\
(\mathbf{m})\end{array}$ & $\begin{array}{c}\text { Buoyancy Force, } \\
\mathbf{F}_{\mathbf{B}}(\mathbf{N}) \text { - Eq. } \mathbf{~}\end{array}$ & $\begin{array}{c}\text { Froude } \\
\text { Number }\end{array}$ \\
\hline 1. & 0.55 & 0.041 & 7.48 & 0.87 \\
\hline 2. & 0.42 & 0.047 & 9.70 & 0.62 \\
\hline 3. & 0.38 & 0.051 & 11.23 & 0.54 \\
\hline 4. & 0.36 & 0.053 & 12.01 & 0.50 \\
\hline 5. & 0.32 & 0.056 & 13.20 & 0.43 \\
\hline 6. & 0.28 & 0.067 & 18.22 & 0.35 \\
\hline 7. & 0.57 & 0.040 & 7.11 & 0.91 \\
\hline 8. & 0.38 & 0.052 & 11.62 & 0.53 \\
\hline 9. & 0.32 & 0.058 & 14.01 & 0.42 \\
\hline 10. & 0.31 & 0.060 & 14.90 & 0.40 \\
\hline 1. & 0.29 & 0.067 & 18.22 & 0.36 \\
\hline 12. & 0.27 & 0.071 & 20.21 & 0.32 \\
\hline 13. & 0.27 & 0.073 & 21.19 & 0.32 \\
\hline 14. & 0.60 & 0.039 & 6.75 & 0.97 \\
\hline 15. & 0.37 & 0.053 & 12.01 & 0.51 \\
\hline 16. & 0.31 & 0.065 & 17.22 & 0.39 \\
\hline 17. & 0.26 & 0.075 & 22.18 & 0.30 \\
\hline
\end{tabular}




\begin{tabular}{|l|l|l|l|l|}
\hline 18. & 0.25 & 0.081 & 25.11 & 0.28 \\
\hline 19. & 0.25 & 0.083 & 26.07 & 0.28 \\
\hline
\end{tabular}

\subsubsection{Drag force}

In previous studies, the drag force on the vehicle was observed in the direction of flow as the vehicle was usually parked. Herein, the study was conducted with a moving vehicle therefore, the influence of drag was observed in two directions i.e. the influence of drag in the direction perpendicular to the flow $\left(\mathrm{D}_{1}\right)$ and the influence of drag in the direction parallel to the vehicle movement $\left(\mathrm{D}_{2}\right)$ as shown in Figure 7. For the estimation of drag force, the submerged area of the vehicle in both directions was estimated separately using AutoCad, SolidWorks and ANSYS, whereas the drag coefficient was set at 1.1 or 1.15 depending on the level of water depth to the chassis height. However, the flow velocity was estimated using velocity meter in both directions and the density of the fluid was taken as $1000 \mathrm{~kg} / \mathrm{m}^{3}$. The influence of drag at $\mathrm{D}_{1}$ was maximum due to the larger area available. Moreover, the flow velocity was high due to the flow direction thus, the resultant drag induced on the vehicle at $\mathrm{D}_{1}$ was strong. On the other hand, the submerged area at $\mathrm{D}_{2}$ was comparatively low and the velocity of the flow was found moderate thus, the resultant drag induced at $\mathrm{D}_{2}$ was nominal and therefore, it has been disregarded in this study for further analysis. The influence of drag force in both directions i.e. at $\mathrm{D}_{1}$ and $\mathrm{D}_{2}$ is shown in Table 3 and 4 , respectively.

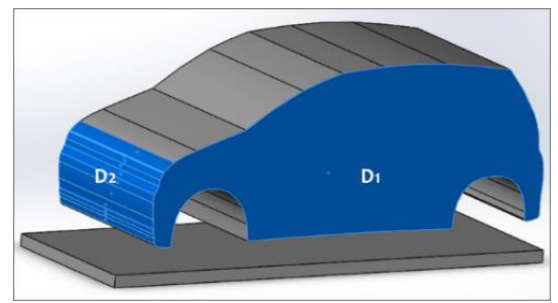

Fig. 7. Influence of drag on a mobile vehicle.

Table 3. Drag Influence at $\mathrm{D}_{1}$.

\begin{tabular}{|c|c|c|c|c|c|c|}
\hline S. No & $\begin{array}{l}\text { Water } \\
\text { Density } \\
\left(\mathrm{kg} / \mathrm{m}^{3}\right)\end{array}$ & $\begin{array}{c}\text { Submerged } \\
\text { Area, Body } \\
\text { only }\left(\mathbf{m}^{2}\right)\end{array}$ & $\begin{array}{l}\text { Submerged } \\
\text { Area of Tires } \\
(\text { Two }),\left(\mathbf{m}^{2}\right)\end{array}$ & $\begin{array}{c}\text { Submerged Area } \\
\text { Projected } \\
\text { Normal to the } \\
\text { Flow, } A_{D}\left(\mathbf{m}^{2}\right)\end{array}$ & $\begin{array}{c}\text { Flow } \\
\text { Velocity, } \\
\mathbf{v}^{2}(\mathrm{~m} / \mathrm{s})\end{array}$ & $\begin{array}{l}\text { Drag } \\
\text { Force, } \\
\text { F }_{\text {D }}(\mathbf{N}) \\
\text { - Eq. } 3\end{array}$ \\
\hline 1. & 1000 & 0.00407 & 0.00406 & 0.00813 & 0.30 & 1.35 \\
\hline 2. & 1000 & 0.00544 & 0.00468 & 0.01012 & 0.18 & 0.98 \\
\hline 3. & 1000 & 0.00640 & 0.00504 & 0.01144 & 0.14 & 0.91 \\
\hline 4. & 1000 & 0.00690 & 0.00519 & 0.01209 & 0.13 & 0.86 \\
\hline 5. & 1000 & 0.00767 & 0.00539 & 0.01306 & 0.10 & 0.74 \\
\hline 6. & 1000 & 0.01107 & 0.00565 & 0.01672 & 0.08 & 0.72 \\
\hline 7. & 1000 & 0.00385 & 0.00395 & 0.00780 & 0.32 & 1.39 \\
\hline 8. & 1000 & 0.00665 & 0.00512 & 0.01177 & 0.14 & 0.93 \\
\hline 9. & 1000 & 0.00821 & 0.00548 & 0.01368 & 0.10 & 0.77 \\
\hline 10. & 1000 & 0.00877 & 0.00565 & 0.01442 & 0.10 & 0.76 \\
\hline 11. & 1000 & 0.01107 & 0.00565 & 0.01672 & 0.08 & 0.77 \\
\hline 12. & 1000 & 0.01245 & 0.00565 & 0.01810 & 0.07 & 0.73 \\
\hline 13. & 1000 & 0.01313 & 0.00565 & 0.01878 & 0.07 & 0.75 \\
\hline 14. & 1000 & 0.00363 & 0.00384 & 0.00747 & 0.36 & 1.48 \\
\hline 15. & 1000 & 0.00690 & 0.00519 & 0.01209 & 0.14 & 0.91 \\
\hline 16. & 1000 & 0.01038 & 0.00565 & 0.01603 & 0.10 & 0.85 \\
\hline 17. & 1000 & 0.01381 & 0.00565 & 0.01946 & 0.07 & 0.72 \\
\hline 18. & 1000 & 0.01584 & 0.00565 & 0.02149 & 0.06 & 0.74 \\
\hline 19. & 1000 & 0.01650 & 0.00565 & 0.02215 & 0.06 & 0.76 \\
\hline
\end{tabular}


Table 4. Drag Influence at $\mathrm{D}_{2}$.

\begin{tabular}{|c|c|c|c|c|c|c|}
\hline S. No & $\begin{array}{l}\text { Water } \\
\text { density } \\
\left(\mathrm{kg} / \mathrm{m}^{3}\right)\end{array}$ & $\begin{array}{c}\text { Submerged } \\
\text { Area, Body } \\
\text { only }\left(\mathbf{m}^{2}\right)\end{array}$ & $\begin{array}{l}\text { Submerged } \\
\text { Area of Tires } \\
\text { (Two), }\left(\mathbf{m}^{2}\right)\end{array}$ & $\begin{array}{c}\text { Submerged Area } \\
\text { Parallel to } \\
\text { Vehicle } \\
\text { Movement, } A_{D} \\
\left(\mathbf{m}^{2}\right)\end{array}$ & $\begin{array}{c}\text { Flow } \\
\text { Velocity, } \\
\mathbf{v}^{2}(\mathrm{~m} / \mathrm{s})\end{array}$ & $\begin{array}{l}\text { Drag } \\
\text { Force, } \\
\text { F }_{\mathbf{D}}(\mathbf{N}) \\
- \text { Eq. } 3\end{array}$ \\
\hline 1. & 1000 & 0.00168 & 0.00076 & 0.00244 & 0.01 & 0.013 \\
\hline 2. & 1000 & 0.00224 & 0.00076 & 0.00300 & 0.01 & 0.017 \\
\hline 3. & 1000 & 0.00264 & 0.00076 & 0.00340 & 0.01 & 0.019 \\
\hline 4. & 1000 & 0.00285 & 0.00076 & 0.00361 & 0.01 & 0.020 \\
\hline 5. & 1000 & 0.00316 & 0.00076 & 0.00392 & 0.01 & 0.022 \\
\hline 6. & 1000 & 0.00457 & 0.00076 & 0.00533 & 0.01 & 0.029 \\
\hline 7. & 1000 & 0.00159 & 0.00076 & 0.00235 & 0.01 & 0.013 \\
\hline 8. & 1000 & 0.00274 & 0.00076 & 0.00350 & 0.01 & 0.019 \\
\hline 9. & 1000 & 0.00339 & 0.00076 & 0.00415 & 0.01 & 0.023 \\
\hline 10. & 1000 & 0.00362 & 0.00076 & 0.00438 & 0.01 & 0.024 \\
\hline 11. & 1000 & 0.00457 & 0.00076 & 0.00533 & 0.01 & 0.029 \\
\hline 12. & 1000 & 0.00513 & 0.00076 & 0.00589 & 0.01 & 0.032 \\
\hline 13. & 1000 & 0.00542 & 0.00076 & 0.00618 & 0.01 & 0.034 \\
\hline 14. & 1000 & 0.00150 & 0.00076 & 0.00226 & 0.01 & 0.012 \\
\hline 15. & 1000 & 0.00285 & 0.00076 & 0.00361 & 0.01 & 0.020 \\
\hline 16. & 1000 & 0.00428 & 0.00076 & 0.00504 & 0.01 & 0.028 \\
\hline 17. & 1000 & 0.00570 & 0.00076 & 0.00646 & 0.01 & 0.036 \\
\hline 18. & 1000 & 0.00653 & 0.00076 & 0.00729 & 0.01 & 0.040 \\
\hline 19. & 1000 & 0.00681 & 0.00076 & 0.00757 & 0.01 & 0.042 \\
\hline
\end{tabular}

\subsubsection{Friction force}

For the estimation of friction force, the range of friction coefficient has been considered between $\mu=0.3$ to $\mu=1.0$ for the vehicles parked in the flooding condition. Herein the influence of friction force was calculated in two directions similar to the influence of drag force. The friction coefficient in both the cases was experimentally determined as shown in Figure 8 . The rolling friction (caused by the moving tires) was estimated to be 0.092 , whereas the friction between the tires and ground surface (parallel to the direction of flow) was found to be 0.52 . The friction force attained at different water depths and flow velocities is shown in Table 5 .

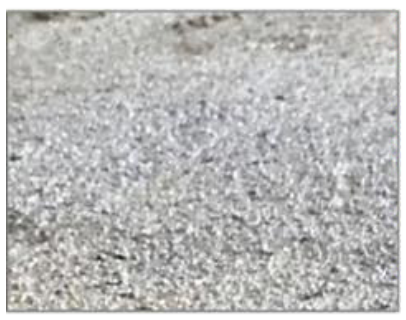

(a)

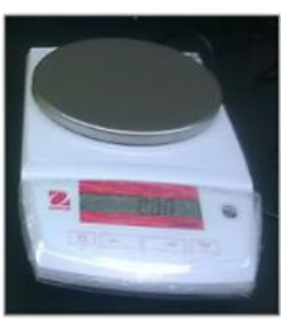

(b)

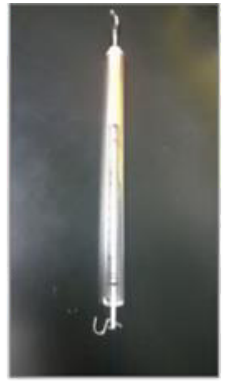

(c)

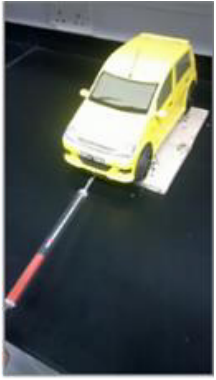

(d)

Fig. 8. Friction coefficient (a) Designed platform, (b) Weighing machine, (c) Spring balance and (d) Horizontal force estimation on wet surface. 
Table 5. Friction Force.

\begin{tabular}{|c|c|c|c|c|c|}
\hline S. No & $\begin{array}{l}\text { Net Weight } \\
\text { of Vehicle } \\
\text { (N) }\end{array}$ & $\begin{array}{c}\text { Rolling } \\
\text { Friction } \\
\text { Coefficient } \\
\left(\mu_{\mathrm{RO}}\right)\end{array}$ & $\begin{array}{c}\text { Rolling Friction } \\
\text { Force, } F_{\text {Ro }}(\mathrm{N}) \text { - } \\
\text { Eq. } 6\end{array}$ & $\begin{array}{c}\text { Friction } \\
\text { Coefficient } \\
(\mu)\end{array}$ & $\begin{array}{c}\text { Friction } \\
\text { Force, } \mathrm{F}_{\mathrm{R}}(\mathrm{N}) \\
- \text { - Eq. } 4\end{array}$ \\
\hline 1. & 1.15 & 0.092 & 0.12 & 0.52 & 0.60 \\
\hline 2. & -1.07 & 0.092 & -0.11 & 0.52 & -0.55 \\
\hline 3. & -2.60 & 0.092 & -0.26 & 0.52 & -1.35 \\
\hline 4. & -3.38 & 0.092 & -0.34 & 0.52 & -1.76 \\
\hline 5. & -4.57 & 0.092 & -0.46 & 0.52 & -2.38 \\
\hline 6. & -9.59 & 0.092 & -0.96 & 0.52 & -4.99 \\
\hline 7. & 1.52 & 0.092 & 0.15 & 0.52 & 0.79 \\
\hline 8. & -2.99 & 0.092 & -0.30 & 0.52 & -1.55 \\
\hline 9. & -5.38 & 0.092 & -0.54 & 0.52 & -2.80 \\
\hline 10. & -6.27 & 0.092 & -0.63 & 0.52 & -3.26 \\
\hline 11. & -9.59 & 0.092 & -0.96 & 0.52 & -4.99 \\
\hline 12. & -11.58 & 0.092 & -1.16 & 0.52 & $\begin{array}{l}-6.02 \\
\end{array}$ \\
\hline 13. & -12.57 & 0.092 & -1.26 & 0.52 & -6.53 \\
\hline 14. & 1.88 & 0.092 & 0.19 & 0.52 & 0.98 \\
\hline 15. & -3.38 & 0.092 & -0.34 & 0.52 & -1.76 \\
\hline 16. & -8.59 & 0.092 & -0.86 & 0.52 & -4.47 \\
\hline 17. & -13.55 & 0.092 & -1.36 & 0.52 & -7.05 \\
\hline 18. & -16.48 & 0.092 & -1.66 & 0.52 & -8.57 \\
\hline 19. & -17.44 & 0.092 & -1.75 & 0.52 & -9.07 \\
\hline
\end{tabular}

\subsubsection{Driving force}

The car engine provides driving force when it just begins to move, this driving force is greater than the opposing friction force on the wheels. Therefore, the vehicle accelerates in the direction of the resultant force. Once moving, the vehicles pushes the fluid out of the way which exerts a force on the car opposite to its direction. This force is called fluid resistance which increases as the speed of the car increases [32]. However, the driving force caused by the vehicle engine estimated during experimental runs is shown in Table 6.

Table 6. Driving Force.

\begin{tabular}{|c|c|c|c|c|c|c|c|c|}
\hline S. No & $\begin{array}{c}\text { Distance } \\
(\mathbf{m}), \mathbf{D}_{\mathbf{1}}\end{array}$ & $\begin{array}{c}\text { Time } \\
(\mathbf{s}), \mathbf{T}_{\mathbf{1}}\end{array}$ & $\begin{array}{c}\text { Vehicle } \\
\text { Velocity } \\
(\mathbf{m} / \mathbf{s}), \mathbf{V}_{\mathbf{1}}\end{array}$ & $\begin{array}{c}\text { Distance } \\
(\mathbf{m}), \mathbf{D}_{\mathbf{2}}\end{array}$ & $\begin{array}{c}\text { Time } \\
(\mathbf{s}), \mathbf{T}_{\mathbf{2}}\end{array}$ & $\begin{array}{c}\text { Vehicle } \\
\text { Velocity } \\
(\mathbf{m} / \mathbf{s}), \mathbf{V}_{\mathbf{2}}\end{array}$ & $\begin{array}{c}\text { Acceleration } \\
\left(\mathbf{m} / \mathbf{s}^{\mathbf{2}} \mathbf{)}\right.\end{array}$ & $\begin{array}{c}\text { Driving } \\
\mathbf{F o r c e} \\
\mathbf{( N )}\end{array}$ \\
\hline 1. & 0.3048 & 1.97 & 0.15 & 0.6096 & 4.27 & 0.143 & 0.002 & 0.00169 \\
\hline 2. & 0.3048 & 1.91 & 0.16 & 0.6096 & 4.15 & 0.147 & 0.002 & 0.00184 \\
\hline 3. & 0.3048 & 1.86 & 0.16 & 0.6096 & 4.30 & 0.142 & 0.004 & 0.00316 \\
\hline 4. & 0.3048 & 1.74 & 0.18 & 0.6096 & 4.35 & 0.140 & 0.006 & 0.00506 \\
\hline 5. & 0.3048 & 1.92 & 0.16 & 0.6096 & 4.25 & 0.143 & 0.002 & 0.00219 \\
\hline 6. & 0.3048 & 1.94 & 0.16 & 0.6096 & 4.31 & 0.141 & 0.003 & 0.00221 \\
\hline 7. & 0.3048 & 1.84 & 0.17 & 0.6096 & 4.69 & 0.13 & 0.005 & 0.00481 \\
\hline 8. & 0.3048 & 1.66 & 0.18 & 0.6096 & 4.28 & 0.14 & 0.007 & 0.00610 \\
\hline 9. & 0.3048 & 1.80 & 0.17 & 0.6096 & 4.35 & 0.14 & 0.005 & 0.00418 \\
\hline 10. & 0.3048 & 1.89 & 0.16 & 0.6096 & 4.60 & 0.13 & 0.004 & 0.00390 \\
\hline 11. & 0.3048 & 1.87 & 0.16 & 0.6096 & 4.59 & 0.13 & 0.005 & 0.00411 \\
\hline 12. & 0.3048 & 1.90 & 0.16 & 0.6096 & 4.69 & 0.13 & 0.005 & 0.00407 \\
\hline 13. & 0.3048 & 1.92 & 0.16 & 0.6096 & 4.68 & 0.13 & 0.004 & 0.00380 \\
\hline 14. & 0.3048 & 1.04 & 0.29 & 0.6096 & 3.18 & 0.19 & 0.024 & 0.02115 \\
\hline 15. & 0.3048 & 1.15 & 0.27 & 0.6096 & 2.99 & 0.20 & 0.015 & 0.01301 \\
\hline 16. & 0.3048 & 1.10 & 0.28 & 0.6096 & 3.79 & 0.16 & 0.024 & 0.02093 \\
\hline 17. & 0.3048 & 1.41 & 0.22 & 0.6096 & 4.28 & 0.14 & 0.013 & 0.01141 \\
\hline 18. & 0.3048 & 1.71 & 0.18 & 0.6096 & 4.13 & 0.15 & 0.005 & 0.00462 \\
\hline 19. & 0.3084 & 1.72 & 0.18 & 0.6096 & 4.15 & 0.15 & 0.006 & 0.00486 \\
\hline
\end{tabular}




\subsection{Instability Modes}

The vehicle stability lost by the hydrodynamic mechanisms can be recognized either by sliding and floating as shown in Figure 9.
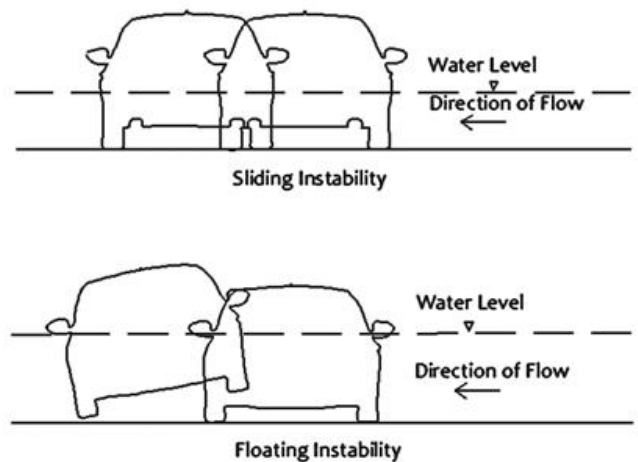

Fig. 9. Instability modes.

For parked vehicles, sliding instability occurs when the horizontal force exerted by water on one or more car panels is greater than the vertical restoring force which is dependent on the friction between the road surface and car tires, vehicle mass, lift force and buoyancy force [11]. However, for the vehicles in motion, the criterion of sliding instability differs. It occurs when the drag force exerted by the water exceeds the friction force (both rolling friction and the friction parallel to the direction of flow) between the tires and the ground as well as the driving force caused by the vehicle engine. Thus, the mode of sliding instability for the moving vehicles can be given as:

$$
\mathrm{F}_{\mathrm{D}}>\mathrm{F}_{\mathrm{RO}}+\mathrm{F}_{\mathrm{R}}+\mathrm{F}_{\mathrm{DV}}
$$

On the other hand, the mode of floating instability is same for both the cases i.e. parked vehicle and moving vehicle. It usually occurs when the vertical pushing forces exceed vehicle weight [3]. This type of instability usually occurs when the flow depth is high and the velocity is low. Thus, the mode of floating instability in this case can be given as:

$$
\mathrm{F}_{\mathrm{B}}>\mathrm{W}_{\mathrm{T}}
$$

where, $F_{B}$ is the buoyancy force and $\mathrm{W}_{\mathrm{T}}$ is the weight of vehicle.

A further mode of instability which occurs due to overturning is called toppling instability. However, this stability appears to be restricted to vehicles which are already sliding or floating. Therefore, this form of instability has been excluded in this study from further analysis [11].

Table 7 shows the floating instability computed through comparison between $F_{B}$ and $W_{T}$, whereas Table 8 shows sliding instability computed through comparison between $F_{D}, F_{R O}$, $\mathrm{F}_{\mathrm{R}}$ and $\mathrm{F}_{\mathrm{DV}}$.

Table 7. Floating instability.

\begin{tabular}{|c|c|c|c|}
\hline S. No & $\mathbf{F}_{\mathbf{B}} \mathbf{( N )}$ & $\mathbf{W}_{\mathbf{T}}(\mathbf{N})$ & $\begin{array}{c}\text { Floating Instability } \\
\left(\mathbf{F}_{\mathbf{B}}>\mathbf{W}_{\mathbf{T}}\right)\end{array}$ \\
\hline 1. & 7.48 & 8.628 & $\times$ \\
\hline 2. & 9.70 & 8.628 & $\checkmark$ \\
\hline 3. & 11.23 & 8.628 & $\checkmark$ \\
\hline 4. & 12.01 & 8.628 & $\checkmark$ \\
\hline 5. & 13.20 & 8.628 & $\checkmark$ \\
\hline 6. & 18.22 & 8.628 & $\checkmark$ \\
\hline 7. & 7.11 & 8.628 & $\times$ \\
\hline
\end{tabular}




\begin{tabular}{|c|c|c|c|}
\hline 8. & 11.62 & 8.628 & $\checkmark$ \\
\hline 9. & 14.01 & 8.628 & $\checkmark$ \\
\hline 10. & 14.90 & 8.628 & $\checkmark$ \\
\hline 11. & 18.22 & 8.628 & $\checkmark$ \\
\hline 12. & 20.21 & 8.628 & $\checkmark$ \\
\hline 13. & 21.19 & 8.628 & $\checkmark$ \\
\hline 14. & 6.75 & 8.628 & $\times$ \\
\hline 15. & 12.01 & 8.628 & $\checkmark$ \\
\hline 16. & 17.22 & 8.628 & $\checkmark$ \\
\hline 17. & 22.18 & 8.628 & $\checkmark$ \\
\hline 18. & 25.11 & 8.628 & $\checkmark$ \\
\hline 19. & 26.07 & 8.628 & $\checkmark$ \\
\hline
\end{tabular}

Table 8. Sliding instability.

\begin{tabular}{|c|c|c|c|c|c|c|}
\hline S. No & $\begin{array}{c}\text { Flow } \\
\text { Velocity } \\
(\mathbf{m} / \mathbf{s})\end{array}$ & $\mathbf{F}_{\mathbf{D}}(\mathbf{N})$ & $\mathbf{F}_{\mathbf{R O}}(\mathbf{N})$ & $\mathbf{F}_{\mathbf{R}}(\mathbf{N})$ & $\mathbf{F}_{\mathbf{D V}}(\mathbf{N})$ & $\begin{array}{c}\text { Sliding Instability } \\
\left(\mathbf{F}_{\mathbf{D}}>\mathbf{F}_{\mathbf{R O}}+\mathbf{F}_{\mathbf{R}}+\mathbf{F}_{\mathbf{D V}}\right)\end{array}$ \\
\hline 1. & 0.55 & 1.35 & 0.12 & 0.60 & 0.00169 & $\checkmark$ \\
\hline 7. & 0.57 & 1.39 & 0.15 & 0.79 & 0.00481 & $\checkmark$ \\
\hline 14. & 0.60 & 1.48 & 0.19 & 0.98 & 0.02115 & $\checkmark$ \\
\hline
\end{tabular}

\subsection{Incipient Velocity Formula Validation}

To assess the prediction accuracy of the proposed formula, experimental runs with 1:10 scaled die-cast model vehicle were conducted to determine the instability modes, a vehicle could face in floodwaters. Herein, the incipient velocity formula for a moving vehicle under partially submerged conditions was analysed based on the pattern of sliding instability. Due to flume limitations, experimental runs were conducted under sub-critical flow conditions. Figure 10 shows the linear regression using the least square method by comparing the observed incipient velocities obtained using the scaled model and calculations from the derived formula. The predicted velocities from the derived formula are in good agreement with the observed data for all three points with the correlation coefficient of 0.99 . Therefore, the formula appears to be useful of estimating incipient velocities for the prototype using Froude similarity. Herein, the outcomes of the study have not been proposed for the prototype and are only limited to scaled model.

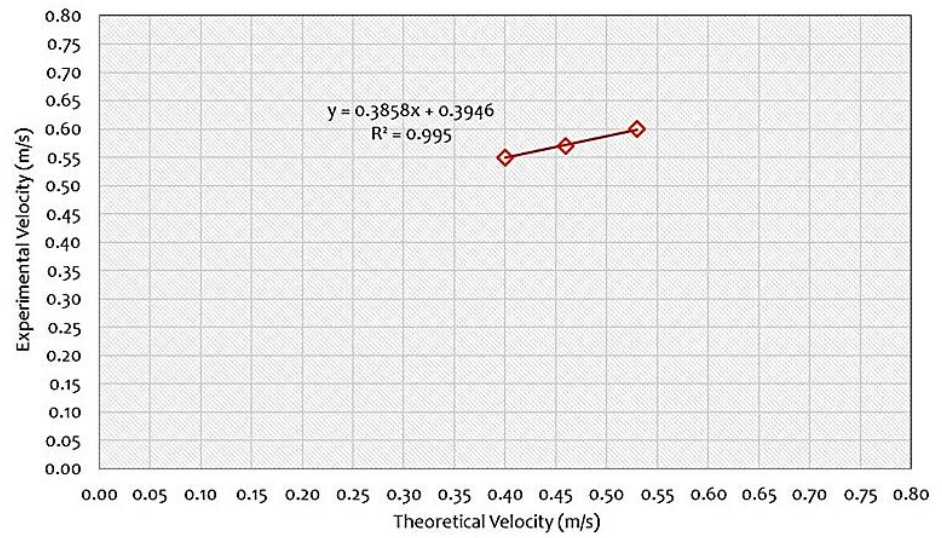

Fig. 10. Formula validation with experimental data. 


\section{Conclusions}

In the current study, the hydrodynamic response of a vehicle moving in floodwater was studied and an incipient velocity formula based on the mechanical theory of sliding equilibrium was proposed. With that regards, a small scale diecast model vehicle (1:10) was used and its response towards the potential forces caused by the flowing water at different increments was noticed. The main findings have highlighted that: (i) the influence of drag force was found dominant at $\mathrm{D}_{1}$ due to the direction of flow and larger available area, whereas at $\mathrm{D}_{2}$ it was nominal due to moderate flow velocity and small submerged area, (ii) the friction coefficient values were experimentally determined and it was found that the value of friction coefficient while rolling was very low i.e. 0.092. On the other hand, the value of friction coefficient parallel to the direction of flow was found to be 0.52 , (iii) for all instability threshold points, the incipient velocity increased with the decrease in depth and vice versa, (iv) the critical water depth at which the up-thrust force governed was observed when the water depth exceeded $0.0457 \mathrm{~m}$. Below critical depth, sliding instability governed until the drag force imposed by the flowing water was greater than the frictional force between the tires and floodplain surface, and the driving force, lastly (v) the predicted velocities from the derived formula were in good agreement with the observed data for all three points with the correlation coefficient of 0.99 .

The outcomes of the study provide a preliminary criterion of hazard level for the vehicles moving in floodwaters. Herein, the study was observed under partial submergence in subcritical flow conditions. Moreover, the study was performed on the flat road conditions with the direction of flow perpendicular to the vehicle movement. Thus, for the assessment of the forces imposed by the water on the flooded vehicles under more real and complex scenarios, studies with the different vehicles: varying in shape, aerodynamic design and weight need to be conducted.

\section{Acknowledgements}

This study was undertaken at Universiti Teknologi PETRONAS. This research was supported by the Technology Innovation Program (Grant No.: 10053121) funded by the Ministry of Trade, Industry \& Energy (MI, Korea). The authors would also like to thank for the great support of POSTECH, Republic of Korea.

\section{References}

1. G. Smith, (2015). Expert opinion: Stability of people, vehicles and buildings in flood water. Water Research Laboratory, Technical Report 2015/11. University of New South Wales. Sydney, Australia.

2. S.M.H. Shah, Z. Mustaffa and Yusof, K.W., (2017). Disasters worldwide and floods in the malaysian region: a brief review. Indian Journal of Science and Technology,10(2).doi:10.17485/ijst/2017/v10i2/110385

3. E. Martínez-Gomariz, M. Gómez, B. Russo, and S. Djordjevic, 2018. Stability criteria for flooded vehicles: a state-of-the-art review. Journal of Flood Risk Management, 11(S2), S817-S826. doi:10.1111/jfr3.12262

4. O. Mok, (2017). Vehicles stuck in the flood at jalan air itam in george town - penang. http://media.themalaymailonline.com/print/malaysia/flash-floods-hit-penang-rivers-atdangerouslevel. 
5. J. Sanyal and Lu, X.X., (2006) GIS-based flood hazard mapping at different administrative scales: a case study in gangetic west bengal, india. Singapore Journal of Tropical Geography, 27(2), 207-220.

6. R. Vandrie, Simon, M., and Schymitzek, I., (2008) HAZARD:-Is there a better definition? \& Impact of Not accounting for buildings!. 48th Annual Floodplain Management Authorities Conference.

7. B. Russo, Velasco, M., and Suñer, D., 2013. Flood hazard assessment considering climatechangeimpacts-application to barcelona case study using a $1 \mathrm{D} / 2 \mathrm{D}$ detailedcoupledmodel.International Conference on Flood Resilience: Experiences in Asia and Europe.

8. S.R. Abt, Wittier, R.J., Taylor, A., and Love, D.J., (1989) Human stability in a high flood hazard zone. Journal of the American Water Resources Association. 25(4), 881-890.

9. B. Russo, M. Gómez, and F. Macchione, (2013) Pedestrian hazard criteria for flooded urban areas. Natural Hazards. 69(1), 251-265.

10. J. Xia, R.A Falconer, Y. Wang, and X. Xiao (2014) New criterion for the stability of a human body in floodwaters. Journal of Hydraulic Research. 52(1), 93-104.

11. T.D. Shand, R.J. Cox, M.J. Blacka, and G.P. Smith (2011) Appropriate safety criteria for vehicles. Australian Rainfall and Runoff, P10/S2/020. ISBN:978-0-85825-948-5

12. C. Arrighi, F. Castelli, and H. Oumeraci (2016) Effects of flow orientation on the onset of motion of flooded vehicles. Sustainable Hydraulics in the Era of Global Change. 837841. doi: 10.1201/b21902-140

13. J. Xia, F.Y. Teo, B.Lin, and R.A. Falconer (2011) Formula of incipient velocity for flooded vehicles. Natural Hazards. 58(1), 1-14.

14. C. Shu, J. Xia, R.A. Falconer, and B. Lin (2011) Incipient velocity for partially submerged vehicles in floodwaters. Journal of Hydraulic Research, 49(6), 709-717.

15. F.Y. Teo, J. Xia, R.A. Falconer, and B. Lin (2012) Experimental studies on the interaction between vehicles and floodplain flows. International Journal of River Basin Management. 10(2), 149-160.

16. F.Y. Teo, R.A. Falconer, B. Lin, and J. Xia (2012). Investigations of hazard risks relating to vehicles moving in flood. The Journal of Water Resources Management. 1(1), 52-66.

17. Martínez-Gomariz E., Gómez, M., Russo, B., and Djordjevic', S., (2017). A new experiments-based methodology to define the stability threshold for any vehicle exposed to flooding. Urban Water Journal. 1-10. doi: 10.1080/1573062X.2017.1301501

18. A.J. Bonham and R.T. Hattersley (1967) Low level causeways. Water Research Laboratory, Report no. 100. University of New South Wales, Australia.

19. A.D. Gordon and P.B. Stone (1973) Car stability on road floodways. National Capital Development Commission, Report no. 73/12. Water Research Laboratory, University of New South Wales, Australia.

20. Chow, V.T., 1959. Open Channel Hydraulics. New York: McGrawHill.

21. M.V. Biezen (2017) What is rolling fricition. Ch 11: Friction, Mechanical Engineering. http://ilectureonline.com.

22. R.J. Keller and Mitsch, B. (1993) Safety aspects of the design of roadways as floodways. Urban Water Research Association of Australia, Research Report no. 69.

23. K. Toda, T.Ishigaki, and, T. Ozaki (2013) Experiments study on floating car in flooding. International Conference on Flood Resilience: Experiences in Asia and Europe. 
24. J. Xia, R.A. Falconer, X. Xiao and Y. Wang (2014) Criterion of vehicle stability in floodwaters based on theoretical and experimental studies. Natural Hazards. 70(2), 16191630.

25. V. Heller (2011) Scale effects in physical hydraulic engineering models. Journal of Hydraulic Research, 49 (3), 293-306.

26. Yalin, M.S., 1971. Theory of hydraulic models. The Macmillan Press Ltd. doi : 10.1007/978-1-349-00245-0

27. H. Kobus (1980) Hydraulic modelling. German Association for Water Resources and Land Improvement, Bonn.

28. P. Novak (1984) Scaling factors and scale effects in modelling hydraulic structures. Symposium on Scale Effects in Modelling Hydraulic Structures. Technische Akademie, Esslingen, 1-5.

29. S.A. Hughes (1993) Physical models and laboratory techniques in coastal engineering. Advanced Series on Ocean Engineering - Volume 7. World Scientific Publishing Co. Pte. Ltd.

30. H. Martin and R. Pohl (2000) Technische hydromechanik (Technical hydromechanics). Verlag für Bauwesen, Berlin.

31. V. Heller (2007) Massstabseffekte im hydraulischen modell (Scale effect in hydraulic modelling). Wasser Energie Luft. 99 (2), 153-159.

32. A. Royston (2013) Forces and motion. Heinemann Educational Books. 